\title{
A simple method for the determination of the cholesterol esterase activity
}

\author{
Agnieszka Ewa Stępieńn ${ }^{1,2}$ and Mykhailo Gonchar ${ }^{1,2,3}$ \\ 1Department of Biotechnology, Institute of Applied Biotechnology and Basic Science, University of Rzeszow, Kolbuszowa, Poland; ${ }^{2}$ Centre of Ap- \\ plied Biotechnology and Basic Sciences, University of Rzeszow, Kolbuszowa, Poland; ${ }^{3}$ Department of Analytical Biotechnology, Institute of Cell \\ Biology, NAS of Ukraine, Lviv, Ukraine
}

The proposed method determines the activity of cholesterol esterase (CEH) and takes advantage of its ability to catalyze the hydrolysis of cholesterol esters naturally present in human serum. The assay is based on Allain's method of spectrophotometric determination of cholesterol by means of cholesterol oxidase, peroxidase, but using 3,5-dichloro-dihydroxybenzenesulfonic acid (DHBS) as phenolic chromogen and human serum as a source of substrate for the CEH as a novelty. Furthermore, it is characterized by low costs and high precision. It can be employed to control the activity of CE preparations used for the preparation of enzymatic kits for the determination of cholesterol or for screening of potential bacterial enzyme producers.

Key words: cholesterol esterase, cholesterol, activity determination, human serum

Received: 28 November, 2012; revised: 25 July, 2013; accepted: 13 September, 2013; available on-line: 20 September, 2013

\section{INTRODUCTION}

Cholesterol esterase (CEH, EC 3.1.1.13) is present mainly in pancreas, its secretory liquid as well as in such tissues as: liver, epithelial cells, and in blood. It is essential in lipoprotein metabolism catalyzing the hydrolysis of cholesterol esters to free cholesterol and fatty acids (Cook et al., 1983). ORF (Tanaka et al. 1999) coding for cholesterol esterase is localized on human chromosome 10 (locus 10q23.2-q23.3). This gene (LIPA, lysosomal lipase gene), also referred to as lysosomal acid lipase gene (LAL or LIPA) or acid cholesterol ester hydrolase gene, has a variable number of tandem repeats (VNTR). Mutations in the LIPAgene result in disorders of esterase synthesis. Deficiency of this type of lipase that takes part in cleaving some cellular lipids, leads to the accumulation of cholesterol esters and triglycerides in the cells and tissues of spleen, liver, bone marrow, small intestine, adrenal gland, or lymph nodes. Such kinds of disorders are defined as cholesterol ester storage disease (CESD) and Wolman disease (WD) (Anderson et al., 1993; 1994). The clinical profile includes multi-organ disorders caused by cholesterol metabolic transformation failures. The activity level of cholesterol esterase in blood serum in CESD equals to $2.7 \pm 0.7 \mathrm{pmol} \cdot \mathrm{min}^{-1} \cdot \mathrm{mg}^{-1}$ and in WD is equal to $2.8 \pm 0.9 \mathrm{pmol} \cdot \mathrm{min}^{-1} \cdot \mathrm{mg}^{-1}$, and is very low as compared to the standard level of $141 \pm 16.9 \mathrm{pmol} \cdot \mathrm{min}^{-1} \cdot \mathrm{mg}^{-1}$ (Anderson et al., 1999).

$\mathrm{CEH}$ is produced by macrophages in order to defend the human organism against introduced foreign matter, e.g. medical implants (Christenson et al., 2006). Using polymers as biomaterials is limited by their sensitivity to enzymatic degradation in an organism. It is known that polymers containing in their structure the ester bond, such as PLA, undergo enzymatic degradation of cholesterol esterase having the capacity to hydrolyse these bonds (Liu et al., 2001).

The availability of a simple and valid method to determine cholesterol esterase activity will enable the selection of the best biomaterials resistant to enzymatic degradation. The study of biodegradation of biocompatible polymers by different enzymes in vitro is very important to predict their potential impact on implants.

Different methods for the estimation of the enzyme activity have been developed. Loginov et al. (1987) determined the activity of $\mathrm{CEH}(5 \mathrm{mU} / \mathrm{ml})$, present in human duodenum, using a fluorometric approach because of the low value of $\mathrm{CEH}$ activity. They used cholesterol ester of 0 -coumaric acid as a substrate.

Other scientists (Tanga et al., 2003 and Christenson et al., 2006) in their study of CEH isolated from cattle pancreas (Sigma-Aldrich product) used its ability to hydrolyze the $p$-nitrophenyl acetate in the presence of phosphate buffer with $\mathrm{pH}$ 7.0.

Determining the CEH activity, Pioruńska-Stolzmann and others (2001) focused on human blood. They isolated the enzyme with the activity of $7.2 \pm 0.9 \mathrm{mU} / \mathrm{mg}$ using the ester of oleic acid and cholesterol as substrates.

Cholesterol esterase is mainly used in clinical studies to determine the level of cholesterol in human blood (Uwajima et al., 1975). The determination is based on the method of Allain and Trinder (Allain et al., 1974), by monitoring generated free cholesterol in the reaction catalyzed by cholesterol oxidase. Finally, cholesterol is converted to cholest-4-en-3-one and hydrogen peroxide, which in reaction with phenol and 4-aminoantipyrine in the presence of peroxidase forms a red colored chinoimine derivative. Colour intensity is directly proportional

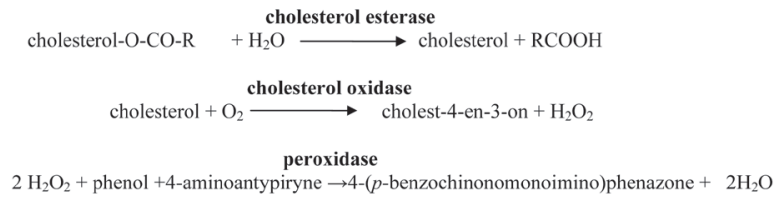

Figure 1. Enzymatic reactions in the determination of cholesterol using the method of Allian et al. (1974)

e-mail: astepien@univ.rzeszow.p

Abbreviations: CEH, Cholesterol esterase; CESD, cholesterol ester storage disease; LIPA, lysosomal lipase gene; VNTR, variable number of tandem repeats; WD, Wolman disease. 
to the amount of cholesterol having a maximum absorption at a wavelength of $500 \mathrm{~nm}$.

In numerous studies, the protocol for cholesterol esterase activity determination proposed by Sigma company is used. It is based on the method of Allain with some modifications (Gallo et al., 1978; Singh et al., 2006).

The aim of the current study was to develop a method for the determination of cholesterol esterase activity (on the model enzyme from Pseudomonas sp.) and for testing its stability in polymer's biodegradability tests. The method is based on fundamental reaction sequences developed by Allain (Allain et al., 1974) using a natural substrate of cholesterol ester, which is present in human serum and phenolic chromogen as ingredients of the reaction mixture - 3,5 dichloro-dihydroxybenzenesulfonic acid (DHBSA) with the molar extinction of the final dye $\left(15.6 \cdot 10^{3} \mathrm{M}^{-1} \cdot \mathrm{cm}^{-1}\right)$.

\section{MATERIALS AND METHODS}

The reaction mixture. $0.6 \% \mathrm{~m} / \mathrm{v} \quad\left(\mathrm{NH}_{4}\right)_{2} \mathrm{HPO}_{4}$, $0.334 \%(\mathrm{~m} / \mathrm{v}) \quad \mathrm{NH}_{4} \mathrm{H}_{2} \mathrm{PO}_{4}, 0.017 \%$ (m/v) 4-aminoantypiryne, $0.0086 \%(\mathrm{~m} / \mathrm{v})$ sodium cholate, $0.002 \%(\mathrm{~m} / \mathrm{v})$ cholesterol oxidase (Roche, $17.7 \mathrm{U} / \mathrm{mg}), 0.46 \cdot 10^{-3 \%} \mathrm{(m} / \mathrm{v}$ ) horseradish peroxidase (Fluka, $150 \mathrm{U} / \mathrm{mg}), 0.066 \%(\mathrm{~m} / \mathrm{v})$ DHBSA (Sigma-Aldrich) water solutions and $0.02 \%$ (v/v) detergent Triton X-100 (20\%).

The composition of the reaction mixture was developed in the Institute of Cell Biology (Lviv) for the determination of cholesterol in human blood. The choice of DHBSA as a chromogen was made taking into account its excellent solubility and better stability (a low autooxidation rate) when compared to phenol.

Cholesterol esterase solution $(50 \mathrm{U} / \mathrm{ml})$. Cholesterol esterase (5 KU/42 mg, Roche) was dissolved in $50 \mathrm{mM}$ phosphate buffer, $\mathrm{pH} 7.0$ to the concentration $0.42 \mathrm{mg} / \mathrm{ml}$ and sterilized by filtration though filter (Millipore, $0.22 \mu \mathrm{m})$.

Analytical procedures. Depletion of free cholesterol in the serum. $5 \mu \mathrm{l}$ of sterile human serum was added to $1 \mathrm{ml}$ of reaction mixture to deplete a free cholesterol. The incubation was carried out for $10 \mathrm{~min}$ at $37^{\circ} \mathrm{C}$, simultanously monitoring the coloured product at the wavelength of $516 \mathrm{~nm}$ in comparison with a control sample containing only distilled water.

Determination of exogenous activity of cholesterol esterase. $10 \mu \mathrm{l}$ cholesterol esterase analyzed the appropriate dilution of $10,12.5,25,100,500$-foldCEH solution $(50 \mathrm{U} / \mathrm{ml})$ was added to $1 \mathrm{ml}$ of the reaction mixture after cholesterol depletion. The incubation was continued at $37^{\circ} \mathrm{C}$ for $10 \mathrm{~min}$, measuring the amount of coloured product at the wavelength of $516 \mathrm{~nm}$.

All the measurements were taken using UV-VIS spectrophotometer SpectroLAB.

The activity of $\mathrm{CEH}$ was determined from the slope of linear fragment of absorbance dependence on time after adding CEH aliquot to the reaction mixture (Fig. 2).

Calculations of $\mathbf{C E H}$ activity. The linear range of the plot was treated with Origin 8.00 program to calculate the rate of the reaction. Milimolar extinction coefficient $\varepsilon{ }_{\mathrm{mM}}$ for oxidized DHBSA was accepted as 15.6 $\mathrm{mM}^{-1} \cdot \mathrm{cm}^{-1}$, as determined by calibration with cholesterol.

$$
\operatorname{Activity}(\mathrm{U} / \mathrm{ml})=\frac{1.015 \cdot \text { slope }}{0.01 \cdot 15.66} \mu \mathrm{mole} /(\mathrm{min} \cdot \mathrm{ml}), \text { where }
$$

umole/(min.ml), where 1.015 - total volume of assay $(\mathrm{ml}) ; 0.01-$ volume of enzyme used $(\mathrm{ml}) ; 15.6-$ milimolar extinction coefficient $\varepsilon_{\mathrm{mm}}$ for oxidized DHBSA $\left(\mathrm{mM}^{-1} \cdot \mathrm{cm}^{-1}\right)$.

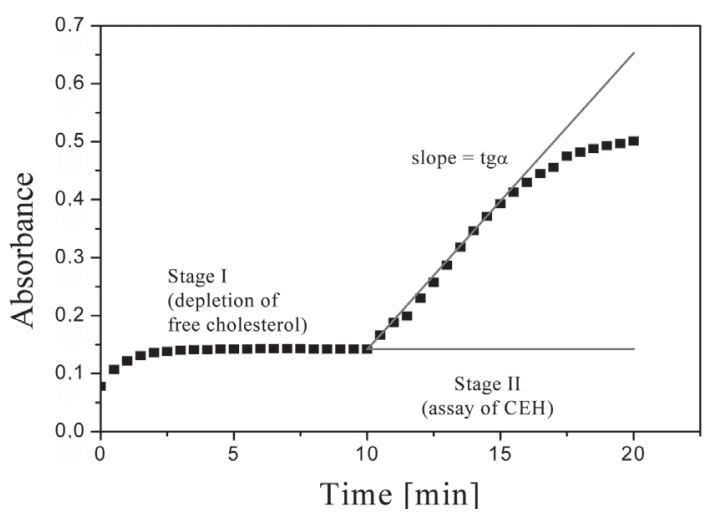

Figure 2. Principle of the CEH activity assay.

Incubation conditions in polymers' biodegradability test: temp. $30^{\circ} \mathrm{C}$, time: 1 month.

\section{RESULTS AND DISCUSSION}

Figure 2 presents two stages of the proposed analytical procedure: I - oxidation of free cholesterol present in human serum and II - determination of exogenous $\mathrm{CEH}$ activity. It is clearly shown that depletion of free cholesterol in serum used as a source of cholesterol esters is finished in the $3 \mathrm{rd} \mathrm{min}$. After the addition of $\mathrm{CEH}$, a well expressed linear range in kinetics profile suitable for reaction rate calculation it is observed .

The stable saturation effect in the absorbance at stage 1 of the reaction (Fig. 2) is an evidence of a negligible endogenous $\mathrm{CEH}$ activity. This proved the possibility to use a human serum as a natural substrate for the exogenous $\mathrm{CEH}$ activity assay.

The values of the CEH activity after 1 month of incubation at $30^{\circ} \mathrm{C}$ (Table 1 ) of the enzyme in solution are rather comparable to the initial values. These results demonstrate a relatively high stability of the enzyme at the conditions required for testing the biodegradability of polymers used for the production of medical implants. The biodegradability test includes an evaluation of the $\mathrm{CEH}$ activity after the incubation of polymer samples such as polyurethanes in solutions of known initial enzyme activity of this enzyme.

Table 1. Cholesterol esterase activity after incubation for 1 month at $30^{\circ} \mathrm{C}$.

\begin{tabular}{ll}
\hline $\begin{array}{l}\text { CEH activity of the prepared } \\
\text { solutions before, } \mathrm{U} / \mathrm{ml}\end{array}$ & $\begin{array}{l}\text { Determined CEH activity } \\
\text { after, } \mathrm{U} / \mathrm{ml}\end{array}$ \\
\hline $0.1 \pm 0.01$ & $0.08 \pm 0.01$ \\
$0.48 \pm 0.05$ & $0.46 \pm 0.04$ \\
\hline $0.93 \pm 0.05$ & $1.87 \pm 0.03$ \\
\hline $3.85 \pm 0.05$ & $3.80 \pm 0.11$ \\
$4.78 \pm 0.01$ & $4.68 \pm 0.01$ \\
\hline
\end{tabular}

\section{CONCLUSIONS}

The proposed method based on the usage of a new phenolic chromogen DHBSA (as an ingredient of the reaction mixture) and human serum (as a natural source of cholesterol esters) was presented as a sensitive and valid assay for measuring the exogenous $\mathrm{CEH}$ activity.

Interestingly, it can be employed in order to test $\mathrm{CEH}$ commercial preparations as well as to monitor changes in enzyme activity (e g., in polymers' biodegradation 
tests). The biodegradability test involves the evaluation of the degradative activity of CEH to polymers. After a period of incubation of polymers in solution of the enzyme with a known initial activity we assessed the possible change.

\section{REFERENCES}

Allain CC ( 1974) Enzymatic determination of total serum cholesterol. Clin Chem 20: 470-475.

Anderson RA, Byrum RS, Coates PM, Sando GN (1994) Mutations at the lysosomal acid cholesteryl ester hydrolase gene locus in Wolman disease. Proc Natl Acad Sci USA 29: 2718-2722.

Anderson RA, Rao N, Byrum RS, Rothschild CB, Bowden DW, Haywotrh R, Pettenati M (1993) In situ localization of the genetic locus enconding the lysosomal acid lipase/cholesteryl esterase (LIPA) deficient In Wolman disease to chromosome 10q23.2-q23.3. Genomocs 15: 145-147.

Anderson RA, Bryson GM, Parks JS (1999) Lysosomal acid lipase mutations that determine phenotype in wolman and cholesterol ester storage disease. Mol Genet Metab 68: 333-345.

Cook KG (1983) The identity of the cholesteryl ester hydrolase of bovine corpus luteum. Biochem Soc Trans 11: 703.

Cook KG (1983) Cytosolic cholesterol ester hydrolase from bovine corpus luteum. Its purification, identification, and relationship to hormone-sensitive lipase. Biochim Biophys Acta 752: 46-53.

Christensona EM, Patel S, Anderson JM, Hiltnera A (2006) Enzymatic degradation of poly(ether urethane) and poly(carbonate urethane) by cholesterol esterase. Biomaterials 27: 3920-3926.
Gallo LL, Atasoy R, Vahouny GV, Treadwell CR (1978) Enzymatic assay for cholesterol ester hydrolase activity. J Lip Res 19: 913-916.

Loginov A S, Shibaeva LO, Planutis KS, Sadoko VM (1988) Determination of cholesterol esterase activity in human duodenal contents. Bulletin Experim Biol Med 106: 1366-1367.

Liu J W, Zhao Q, (2001) Research progresses on degradation mechanism in vivo and medical applications of polylactic acid. Space Med Eng (Beijing) 14: 308-312.

Pioruńska-Stolzmann M, Iskra M, Majewski W (2001) The activity of cholesterol esterase and ceruloplasmin are inversely related in the serum of men with atherosclerosis obliterans. Med Sci Monit 7: 940945.

Singh S, Solanki PR, Pandey MK, Malhora BD (2006) Cholesterol biosensor on cholesterol esterase, cholesterol oxidase and peroxidase immobilized onto concducting polyaniline films. Sensors and Actuaors B 115: 534-541.

Sigma quality control test procedure http://www.sigmaaldrich.com/ technical-documents/protocols/biology/assay-procedure-for-cholesterol-esterase.html

Tanaka H (1999) Purification and characterization of bovine pancreatic bile salt-activated lipase. I Biochem 125: 883-890.

Tanga YW, Labow RS, Santerre JP (2003) Enzyme induced biodegradation of polycarbonate-polyurethanes: dose dependence effect of cholesterol esterase. Biomaterials 12: 2003-2011.

Taylor AK, Zambaux JL, Klisak I, Mohandas T, Sparkes R S, Schotz MC, Lusis AJ (1991) Carboxyl ester lipase: A highly polymorphic locus on human chromosome 9qter. Genomics 10: 425-431.

Uwajima T, Terada O (1976), Production of cholesterol esterase by Pseudomonas fluorescens. Agric Biol Chem 40: 1605-1609.

Uwajima T (1975) Purification and properties of extracellular cholesterol esterase ester hydrolase of Pseudomonas flourescens. Agric Biol Chem 39: 1511-1512. 